\title{
Atromentin and Leucomelone, the First Inhibitors Specific to Enoyl-ACP Reductase (FabK) of Streptococcus pneumoniae
}

\author{
Chang-Ji Zheng, Mi-Jin Sohn, Won-Gon Kim
}

Received: September 6, 2006 / Accepted: November 23, 2006

(C) Japan Antibiotics Research Association

\begin{abstract}
Two potent inhibitors of FabK, the enoyl-acyl carrier protein (ACP) reductase of Streptococcus pneumoniae, were isolated from the solid state fermentation of an unidentified fungus F010248. Their structures were identified to be atromentin and leucomelone by various spectral analysis. Atromentin and leucomelone inhibited the FabK with $\mathrm{IC}_{50}$ values of 0.24 and $1.57 \mu \mathrm{M}$, respectively, while did not inhibit FabI, the enoyl-ACP reductase of either Escherichia coli or Staphylococcus aureus, even at $200 \mu \mathrm{M}$. Atromentin and leucomelone are the first inhibitors specific to the enoyl-ACP reductase (FabK) of Streptococcus pneumoniae.
\end{abstract}

Keywords atromentin, leucomelone, terphenyl, enoylACP reductase, FabK, Streptococcus pneumoniae

Fatty acid biosynthesis in bacteria is essential to the production of a number of lipid-containing components including the cell membrane. The bacterial fatty acid system (FAS II) utilizes discrete monofunctional enzymes that operate in conjunction with acyl carrier protein (ACP)associated substrates. Mammalian fatty acid synthase (FAS I) differs from FAS II in that lipid biosynthesis is mediated by a single multifunctional enzyme-ACP complex. The differences in prokaryote and eukaryote fatty acid biosynthesis offer an attractive opportunity for selective FASII inhibition which is a potential strategy for the development of antibacterial agents [1 3]. Bacterial enoyl-

W.-G. Kim (Corresponding author), C.-J. Zheng, M.-J. Sohn: Functional Metabolomics Research Center, Korea Research Institute of Bioscience and Biotechnology, Yusong, Daejeon 305806, Republic of Korea, E-mail: wgkim@kribb.re.kr
ACP reductase that catalyzes the final and rate-limiting step in the type II FAS has been validated as a novel target for antibacterial drug development. Indeed, the antibacterial target of triclosan [4], the broad spectrum biocide in a wide range of consumer goods, and isoniazid [5], used in the treatment of tuberculosis for 50 years, have been determined to be the FabI. There are three isoforms, FabI, FabK, and FabL, in enoyl-ACP reductase. FabI is widely distributed in most of bacteria but, FabK is present in few important pathogens such as Streptococcus pneumoniae, Enterococcus faecalis, Clostridium acetobutylicum and Pseudomonas aeruginosa. E. faecalis and P. aeruginosa were known to contain FabI as well as FabK. Therefore, FabK inhibitors will be promising as an antibacterial drug specific to the important respiratory pathogen $S$. pneumonia and required for enoyl reductase therapy to be effective on E. faecalis and $P$. aeruginosa [6 8]. Although there have been a number of reports on the designing and development of FabI inhibitors [9 11], little has been studied for FabK inhibitors. In the course of the screening program for FabK inhibitors from microbial resources, two terphenyl type compounds were isolated from the solid state fermentation of an identified fungus F010248. They are identified as atromentin (1) and leucomelone (2) by spectral analysis. We report here the isolation and FabK-specific inhibitory activity of $\mathbf{1}$ and $\mathbf{2}$ (Fig. 1).

The fungal stain F010248 was isolated from a soil sample that was collected in a corn field around Kongjucity, Chungchongnam-do, Korea. Fermentation was carried out in a liquid culture medium containing $2 \%$ glucose, $0.2 \%$ yeast extract, $0.5 \%$ peptone, $0.05 \% \mathrm{MgSO}_{4}$, and $0.1 \%$ $\mathrm{KH}_{2} \mathrm{PO}_{4}$ (pH 5.7 before sterilization). A piece of the strain F010248 from a mature plate culture was inoculated into a 500-ml Erlenmeyer flask containing $80 \mathrm{ml}$ of the above sterile seed liquid medium and cultured on a rotary shaker 


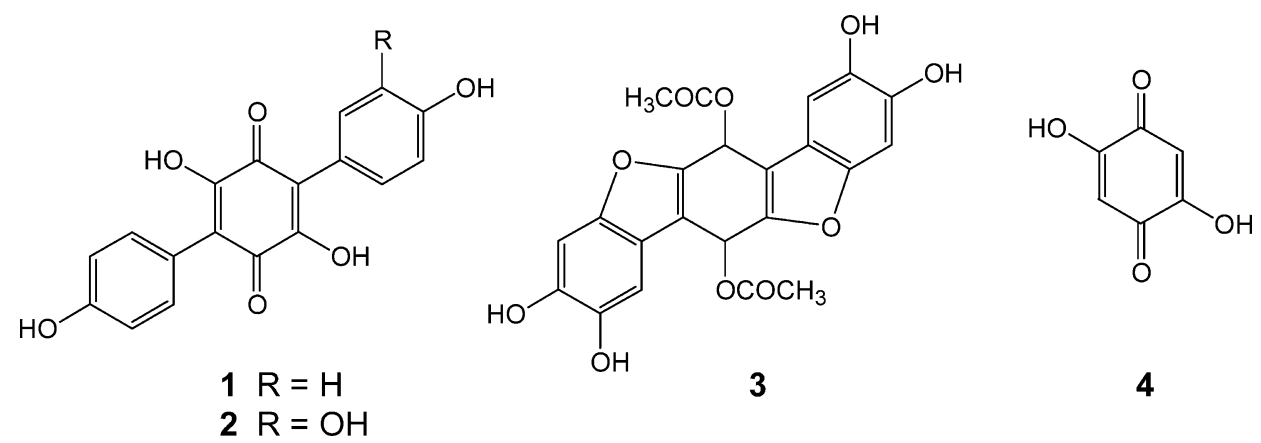

Fig. 1 The structures of atromentin (1), leucomelone (2) and related compounds.

$(150 \mathrm{rpm})$ at $28^{\circ} \mathrm{C}$ for 3 days. For the production of active compounds, $5 \mathrm{ml}$ of the seed culture were transferred into $500 \mathrm{ml}$ Erlenmeyer flasks (54 flasks) containing $80 \mathrm{~g}$ of the bran medium, and cultivated for 7 days at $28^{\circ} \mathrm{C}$. The solid state culture was extracted with acetone, and the extract was concentrated in vacuo to an aqueous solution. The aqueous solution was adjusted to the $\mathrm{pH} 3$, which was then extracted three times with an equal volume of EtOAc. The EtOAc extract was concentrated in vacuo to dryness. The crude extract was subjected to ODS (YMC s-150 $\mu \mathrm{m}$ ) column chromatography, followed by stepwise elution with $\mathrm{MeOH}: \mathrm{H}_{2} \mathrm{O}(10: 90,30: 70,50: 50,70: 30,100: 0)$. The active fractions eluted with both $\mathrm{MeOH}: \mathrm{H}_{2} \mathrm{O}(30: 70)$ and $\mathrm{MeOH}: \mathrm{H}_{2} \mathrm{O}(50: 50)$ were pooled and concentrated in vасио. The residue was applied again to Sephadex LH-20 column and then eluted with $\mathrm{MeOH}$. The active fractions were pooled and concentrated in vacuo. The residue dissolved in $\mathrm{MeOH}$ was further purified by HPLC RP 18 reverse phase HPLC column $\left(20 \times 250 \mathrm{~mm}, \mathrm{YMC} \mathrm{C}_{18}\right)$ chromatography with a photodiode array detector. The active substances or inhibitors eluted with $\mathrm{MeOH}: \mathrm{H}_{2} \mathrm{O}$ $(50: 50)$ containing $0.01 \%$ trifluoroacetic acid at a flow rate of $3 \mathrm{ml} /$ minute to afford $\mathbf{1}(9.7 \mathrm{mg})$ and $2(11.4 \mathrm{mg})$ at retention times of 26.8 and 18.2 minutes, respectively, as black powders. The structures of $\mathbf{1}$ and $\mathbf{2}$ were identified to be atromentin [12,13] and leucomelone [14], respectively, by comparing their spectroscopic data such as UV, mass, ${ }^{1} \mathrm{H}-\mathrm{NMR}$ and ${ }^{13} \mathrm{C}$-NMR data with the values previously reported.

FabK assays were carried out in 96-well microtitre plates by modifying the FabI assay as previously reported [3]. Compounds were evaluated in $100 \mu \mathrm{l}$ assay mixtures containing components specific for each enzyme (see below). Reduction of the trans-2-octenoyl- $N$ acetylcysteamine thioester (t-o-NAC) substrate analog was measured spectrophotometrically by following the UV adsorption of NADH at $340 \mathrm{~nm}$ at $30^{\circ} \mathrm{C}$ for the linear period of the assay. FabK assays contained $100 \mathrm{mM}$ sodium acetate, $\mathrm{pH} 6.5,2.0 \%$ glycerol, $200 \mathrm{mM} \mathrm{NH}_{4} \mathrm{Cl}, 50 \mu \mathrm{M}$ t-oNAC, $200 \mu \mathrm{M}$ NADH, and $150 \mathrm{nM}$ S. pneumoniae FabK. The rate of decrease in the amount of NADH in each reaction well was measured by a microtiter ELISA reader using SOFTmax PRO software (Molecular Devices, California, USA). The inhibitory activity was calculated by the following formula: $\%$ of inhibition $=100 \times[1-($ rate in the presence of compound/rate in the untreated control)]. $\mathrm{IC}_{50}$ values were calculated by fitting the data to a sigmoid equation. An equal volume of dimethyl sulfoxide solvent was used for the untreated control. For FabI assays, $S$. aureus FabI assay contained $50 \mathrm{mM}$ sodium acetate, $\mathrm{pH}$ $6.5,400 \mu \mathrm{M}$ t-o-NAC, $200 \mu \mathrm{M} \mathrm{NADPH}$, and $150 \mathrm{nM}$ Staphylococcus aureus FabI. The Escherichia coli FabI assay contained $50 \mathrm{mM}$ sodium phosphate, $\mathrm{pH}$ 7.5, $200 \mu \mathrm{M}$ t-o-NAC, $200 \mu \mathrm{M}$ NADH and $150 \mathrm{nM} \mathrm{E}$. coli FabI. The inhibitory activity was determined in the same methods as for S. pneumoniae FabK, as described above.

As shown in Fig. 2, 1 and $\mathbf{2}$ showed inhibitory activity on $S$. pneumoniae FabK in a dose-dependant fashion with $\mathrm{IC}_{50}$ values of 0.24 and $1.57 \mu \mathrm{M}$, respectively, while their structurally-related compounds, polyozellin (3) we previously isolated [15] and commercially available 2,5dihydroxy-1,4-benzoquinone (4), did not inhibit the FabK even at $100 \mu \mathrm{M}$. It suggests that both the 2,5-dihydroxy1,4-benzoquinone and the phenol moieties could be important for their activity. To elucidate the mechanism of inhibition by $\mathbf{2}$ on the FabK, a lineweaver-burk plot analysis was conducted (Fig. 3). 2 inhibited S. pneumoniae FabK in a mixed manner with the substrate t-o-NAC-thioester. The $K_{\mathrm{i}}$ and $K_{\mathrm{m}}$ values for $S$. pneumoniae FabK were $4.1 \times 10^{-7} \mathrm{M}$ and $1.9 \times 10^{-4} \mathrm{M}$, respectively.

To evaluate whether $\mathbf{1}$ and $\mathbf{2}$ are specific to FabK, their inhibitory activities on either $E$. coli or $S$. aureus FabI was tested (Table 1). $\mathbf{1}$ and $\mathbf{2}$, however, did not show any inhibitory activity on $E$. coli or $S$. aureus FabI even at $100 \mu \mathrm{M}$ while triclosan, a well-known inhibitor of FabI, as a positive control strongly inhibited on E. coli or S. aureus 
FabI with $\mathrm{IC}_{50}(\mu \mathrm{M})$ values of 0.44 and 1.39 , respectively. This indicates that $\mathbf{1}$ and $\mathbf{2}$ have a specific inhibitory effect on the FabK isoform of enoyl-ACP reductase.

Atromentin and leucomelone did not show antibacterial activity up to $100 \mu \mathrm{g} / \mathrm{ml}$ against $S$. pneumoniae, $P$. aeruginosa and E. faecalis. Some polyphenol compounds have been reported to be pumped out in bacteria [16]. For example, phenolic compounds such as rhein, gossypol, or resveratrol have been reported to be extruded by a multidrug resistance (MDR) pump in P. aeruginosa, E. coli, or Salmonella enterica, since their antibacterial activity was uncovered by the treatment with MDR inhibitors, $\mathrm{MC}_{207110}$ or $\mathrm{INF}_{271}$, or in an MDR mutant. Also, some cathechin gallates or flavanone-3-ols such as fustin and taxifolin were reported not to exhibit antibacterial activity against $E$. coli while other flavonols such as fisetin and quercetin showed antibacterial activity, although all of them inhibited E. coli FabI [11]. AG205, a potent FabK-inhibitory, has been

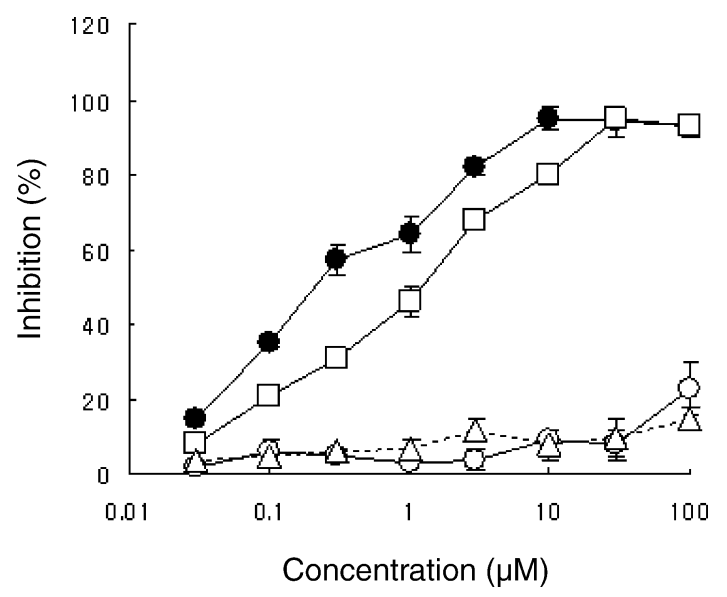

Fig. 2 Inhibitory effects of compounds $\mathbf{1} \sim \mathbf{4}$ on Streptococcus pneumoniae FabK.

The values were represented as the mean \pm S.D. of experiments performed in triplicate. $\bullet, \mathbf{1} ; \square, \mathbf{2} ; \bigcirc, \mathbf{3} ; \triangle, \mathbf{4}$.
A)

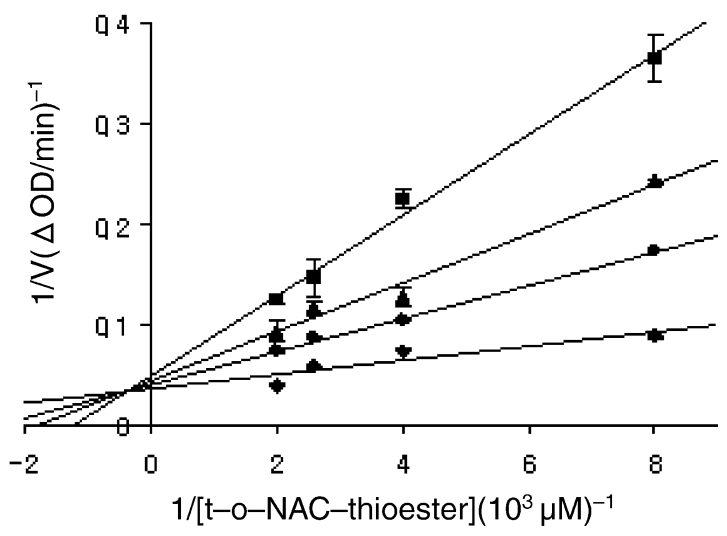

B)

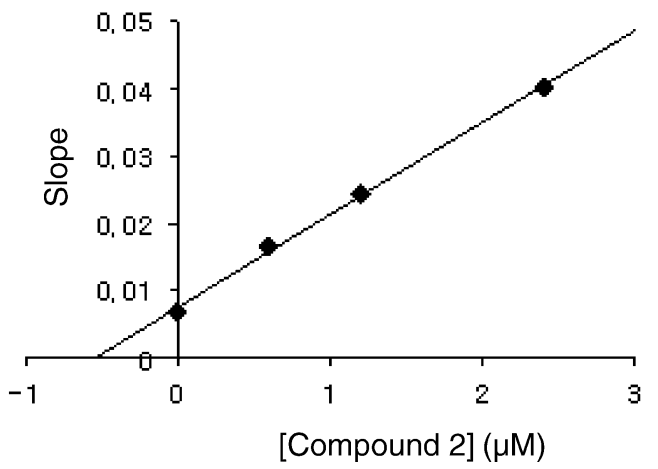

Fig. 3 The mechanism of FabK inhibition by compound $\mathbf{2}$ respective to t-o-NAC thioester $(A)$, and $K_{i}$ determination of compound 2 (B).

(A) The reciprocals of the initial reaction and substrate concentration are plotted. The values were represented as the mean \pm S.D. of experiments performed in triplicate. (B) The slope values of the lines from graph $A$ are plotted versus the inhibitor concentration, affording a line obtained by linear regression. The intercept point of this line with the $x$-axis gives an approximate $K_{i}$ value of $0.41 \mu \mathrm{M}$ for compound $2 . \diamond, 0 \mu \mathrm{M} ; \bullet, 0.6 \mu \mathrm{M} ; \boldsymbol{\Delta}, 1.2 \mu \mathrm{M}$; $\mathbf{\square}, 2.4 \mu \mathrm{M}$.

Table 1 Inhibitory activity of 1, 2 and related compounds on Streptococcus pneumoniae FabK, Escherichia coli Fabl, and Staphylococcus aureus Fabl

\begin{tabular}{ccrr}
\hline & & \multicolumn{1}{c}{$\mathrm{C}_{50}(\mu \mathrm{M})$} & \\
\cline { 2 - 4 } Compounds & Fabl (E. coli) & Fabl (S. aureus) \\
\hline $\mathbf{1}$ & 0.24 & $>200$ & $>200$ \\
$\mathbf{2}$ & 1.57 & $>200$ & $>200$ \\
$\mathbf{3}$ & $>200$ & $>200$ & $>200$ \\
$\mathbf{4}$ & $>200$ & $>200$ & $>200$ \\
Triclosan & $>200$ & 0.44 & 1.39 \\
\hline
\end{tabular}


reported to show reduced activity against some $S$. pneumoniae isolates, which was assumed to be due to an efflux pump [17]. Taken together with these recent studies, our results suggest that the loss of antibacterial effect of atromentin and leucomelone on $S$. pneumoniae is presumably due to the efflux effect of cell wall.

Atromentin which belong to the mushroom pigments and $p$-terphenyl compounds was first described in 1878 by Thörner [18] and reviewed in 2006 by Liu [19]. The structure of atromentin isolated from a lignicolous mushroom Paxillus panuoides and other mushrooms has been spectroscopically elucidated $[12,13]$ and chemically synthesized [20]. Atromentin has been reported to have anticoagulant activity [21]. Leucomelone was first reported as a pigment component of the edible black mushroom Polyporus leucomelas [22] and has been chemically synthesized [14]. However, no biological activity of leucomelone has been reported. The production of atromentin and leucomelone by a soil derived filamentous fungus is reported for the first time in this study.

Few compounds such as indole naphthyridinones, AG205, and AE 848 have been reported to inhibit $S$. pneumoniae FabK $[17,23]$. The indole naphthyridinonebased compound, however, was a non-selective inhibitor since it strongly inhibited the FabI of $S$. aureus and E. coli as well. Inhibitory effects of AG205 and AE 848 against FabI have been not reported yet. As far as we know, atromentin and leucomelone are the first FabK-specific inhibitors.

Acknowledgment This work was supported by the 21C Frontier Microbial Genomics and Application Center Program, Ministry of Science and Technology (Grant MG05-0308-3-0), Republic of Korea.

\section{References}

1. Chan PF, Macarron R, Payne DJ, Zalacain M, Holmes DJ. Novel antibacterials: a genomics approach to drug discovery. Curr Drug Targets Infect Disord 2: 291-308 (2002)

2. Payne DJ, Warren PV, Holmes DJ, Ji Y, Lonsdale JT. Bacterial fatty-acid biosynthesis: a genomic-driven target for antibacterial drug discovery. Drug Discov Today 6: 537-544 (2001)

3. Zheng CJ, Yoo JS, Lee TG., Cho HY, Kim YH, Kim WG. Fatty acid synthesis a target for antibacterial activity of unsaturated fatty acids. FEBS Lett 579: 5157-5162 (2005)

4. McMurry LM, Oethinger M, Levy SB. Triclosan targets lipid synthesis. Nature 394: 531-532 (1998)

5. Rozwarski DA, Grant GA, Barton DHR, Jacobs Jr. WR. Sacchettini JC. Modification of the NADH of the isoniazid target (InhA) from Mycobacterium tuberculosis. Science 279: 98-102 (1998)

6. Heath RJ, White SW, Rock CO. Lipid biosynthesis as a target for antibacterial agents. Prog Lipid Res 40: 467-497 (2001)

7. Campbell JW, Cronan Jr. JE. Bacterial fatty acid biosynthesis: targets for antibacterial drug discovery. Annu Rev Microbiol 55: 305-332 (2001)

8. Marrakchi H, Dewolf Jr. WE, Quinn C, West J, Polizzi BJ, Polizzi BJ, So CY, Holmes DJ, Reed SL, Heath RJ, Payne DJ, Rock CO, Wallis NG. Characterization of Streptococcus pneumoniae enoyl-(acyl-carrier protein) reductase (FabK). Biochem J 370: 1055-1062 (2003)

9. Heerding DA, Chan G, DeWolf Jr. WE, Fosberry AP, Janson CA, Jaworski DD, Mcmanus E, Miller WH, Moore TD, Payne DJ, Qiu X, Rittenhouse SF, Radosti CS, Smith W, Takata DT, Vaidya KS, Yuan CCK, Huffman WF. 1,4Disubstituted imidazoles are potential antibacterial agents functioning as inhibitors of enoyl acyl carrier reductase (FabI). Bioorg Med Chem Lett 11: 2061-2065 (2002)

10. Miller WH, Seefeld MA, Newlander KA, Uzinskas IN, Burgess WJ, Heerding DA, Yuan CCK, Head MS, Payne DJ, Rittenhouse SF, Moore TD, Pearson SC, Berry V, DeWolf Jr. WE, Keller PM, Polizzi BJ, Qiu X, Janson CA, Huffman WF. Discovery of aminopyridine-based inhibitors of bacterial enoyl-ACP reductase (FabI). J Med Chem 45: 3246-3256 (2002)

11. Zhang YM, Rock CO. Evaluation of epigallocatechin gallate and related plant polyphenols as inhibitors of the FabG and FabI reductases of bacterial type II fatty acid synthase. J Biol Chem 279: 30994-31001 (2004)

12. $\mathrm{Hu} \mathrm{L}, \mathrm{Gao} \mathrm{JM}$, Liu JK. Unusual poly(phenylacetyloxy)substituted $1,1^{\prime}: 4^{\prime}, 1^{\prime \prime}$-terphenyl derivatives from fruiting bodies of the basidiomycete Thelephora ganbajun. Helv Chem Acta 84: 3342-3349 (2001)

13. Gaylord MC, Brady LR. Comparison of pigments in carpophores and saprophytic cultures of Paxillus panuoides and Paxillus atrotomentosus. J Pharm Sci 60: 1503-1508 (1971)

14. Edwards RL, Gill M. Constituents of the higher fungi Part XV. 3-(3,4-Dihydroxyphenyl)-2,7,8-trihydroxydibenzofuran1,4-dione, a precursor of thelephoric acid from the fungus Suillus grevillei (Klotsch) sing. [Boletus elegans (Schum. Per fries)]. J Chem Soc Perkin I 351-354 (1975)

15. Hwang JS, Song KS, Kim WG, Lee TH, Kohino H, Yoo ID. Polyozellin, a new inhibitor of prolyl endopeptidase from Polyozellus multiplex. J Antibiot 50: 773-777 (1997)

16. Tegos G, Stermitz FR, Lomovskaya O, Lewis K. Multidrug pump inhibitors uncover remarkable activity of plat antimicrobials. Antimicrob Agents Chemother 46: 3133-3141 (2002)

17. Takahata S, Iida M, Osaki Y, Saito Y, Saito J, Kitagawa H, Ozawa T, Yoshida T, Hoshiko S. AG205, a novel agent directed against FabK of Streptococcus pneumoniae. Antimicrob Agents Chemther 50: 2869-2871 (2006) 
18. Thörner W. Ueber eigen in einer Agaricus-art vorkommenden chinonartigen Körper. Chem Ber 11: 533-535 (1878)

19. Liu JK. Natural terphenyls: Developments since 1877. Chem Rev 106: 2209-2223 (2006)

20. Brewer D, Maass WSG, Taylor A. The effect of fungal growth of some 2,5-dihydroxy-1,4-benzoquinones. Can J Microbiol 23: 845-851 (1977)

21. Khanna JM, Malone MH, Euler KL, Brady LR. Anticoagulant from Hydnellum diabolus. J Pharm Sci 54: 1016-1020 (1965)
22. Aakgi M. Pigment component of Polyporus leucomelas. I. Leucomelone, a pigment. Yakugaku Zasshi 62: 129-134 (1942)

23. Seefeld MA, Miller WH, Newlander KA, Burgess WJ, Dewolf Jr. WE, Elkins PA, Head MS, Jakas DR, Jonson CA, Keller PM, Manley PJ, Moore TD, Payne DJ, Pearson S, Polizzi BJ, QIu X, Rittenhouse SF, Uzinskas IN, Wallis NG, Huffman WF. Indole naphthyridinones as inhibitors of bacterial enoyl-ACP reductases FabI and FabK. J Med Chem 46: 1627-1635 (2003) 